\title{
Paroxysmal dyskinesia
}

INSERM

\section{Source}

INSERM. (1999). Orphanet: an online rare disease and orphan drug data base.

Paroxysmal dyskinesia. ORPHA:1431

Paroxysmal dyskinesia (PD) is a rare heterogenous group of movement disorders manifesting as abnormal involuntary movements that recur episodically and last only a brief time. PD includes paroxysmal kinesigenic dyskinesia (PKD), paroxysmal nonkinesigenic dyskinesia (PNKD), paroxysmal exertion-induced dyskinesia (PED) and a variant form of PKD, infantile convulsion and choreoathetosis (ICCA syndrome) (see these terms). 